\title{
The Renal Clearance of Endogenous Estrogens in Late Pregnancy*
}

\author{
C. Harmon Brown, $\dagger$ Benjamin D. Saffan, $\frac{\ddagger}{\dagger}$ Carolyn M. Howard, and \\ JoHN R. K. PREEDY \\ (From the Department of Medicine, Emory University, Atlanta, Ga.)
}

Although several studies have been published describing the renal excretion of certain steroid hormones $(2,3)$, or groups of hormones and hormone metabolites (4-8), an analysis of the renal clearance of endogenous estrogens has not so far been described. This has been due principally to the lack of adequate chemical methods for the determination of estrogens in plasma. Methods for the determination of plasma estrogens in late pregnancy, however, have recently become available $(9,10)$, and it therefore appeared feasible to investigate the renal excretion of endogenous estrogens in this condition. An inspection of the general level of estrogen concentrations in random samples obtained from subjects in late pregnancy had suggested that the concentration ratio of the three estrogens estrone $(1,3,5$-estratrien-3ol-17-one), estradiol-17 $\beta$ (1,3,5-estratriene-3, $17 \beta$ diol), and estriol (1,3,5-estratriene- $3 \beta, 16 \alpha, 17 \beta$ triol) in plasma might differ from their concentration ratio in urine (11).

A series of pregnant subjects was selected, and renal excretion studies of total $^{1}$ estrone, total estradiol-17 $\beta$, and total estriol were carried out.

\footnotetext{
* Submitted for publication July 17, 1963; accepted October 23, 1963.

This study was supported in part by research grant $\mathrm{AM} 02221$ and training grant TI 5048 from the $\mathrm{Na}$ tional Institute of Arthritis and Metabolic Diseases and by grant G-61-3 of the Life Insurance Medical Research Fund. Part of this work has been published in abstract form (1), and part was presented at the 43rd Meeting of the Endocrine Society, New York, June 1961.

$\dagger$ Postdoctoral fellow, National Institute of Arthritis and Metabolic Diseases.

$\ddagger$ Trainee, National Institute of Arthritis and Metabolic Diseases.

1 In this context "total" is used to describe that amount of each of the three estrogens obtained after acid hydrolysis and ether extraction of plasma and urine samples, as will be apparent from the analytical method used (10). In the subsequent description and discussion the word "total" is usually omitted for brevity.
}

The results were compared with simultaneous studies of endogenous creatinine excretion. The effect of the tubular blocking agent probenecid on plasma concentration, urinary excretion, and renal clearance of each of these hormones was also determined.

\section{Methods}

Clinical material. Primiparous or multiparous women, ages 17 to 40 years, in the last 6 weeks of normal pregnancy were selected from the wards and clinics of Grady Memorial Hospital. There was no evidence of hypertension or of cardiac or renal disease. One patient, however, was found to have symptomless carcinoma of the breast at delivery. There were no stillbirths and no multiple births in this series.

Renal clearance studies. Subjects were studied both as outpatients and in the wards. The outpatients were studied 3 to 4 hours after breakfast, and those in the wards 3 to 4 hours after breakfast or 2 to 3 hours after a liquid lunch. All subjects were given sufficient water orally to establish a diuresis of 3 to $15 \mathrm{ml}$ per minute and adequate water thereafter to maintain a diuresis during the study period. Outpatients were studied in the sitting position, and urine was collected by voiding. Subjects in the wards were studied in the semirecumbent position in bed, and urine was again collected by voiding. In three subjects an indwelling soft rubber catheter was used, the bladder being irrigated with normal saline at the end of each collection period. This procedure, however, was subsequently abandoned, since it was found that adequate collections were obtained by voiding. Urine collection periods were 20 to 90 minutes. These comparatively long periods were necessary to obtain adequate amounts of urinary estrone, estradiol-17 $\beta$ and estriol for analysis. The clearance values given in Figure 3 usually represent the mean of two or three clearance periods. Owing to the necessary length of the clearance period, it was impossible to obtain more than one clearance period in a proportion of subjects. Blood samples were drawn in heparinized syringes at the middle of each collection period. Renal clearance figures were calculated by standard methods (12) from the plasma and urine estrogen concentrations. Plasma and urine endogenous creatinine was measured by the method of Brod and Sirota (13), except that in the plasma determinations a neutral tungstate filtrate was 

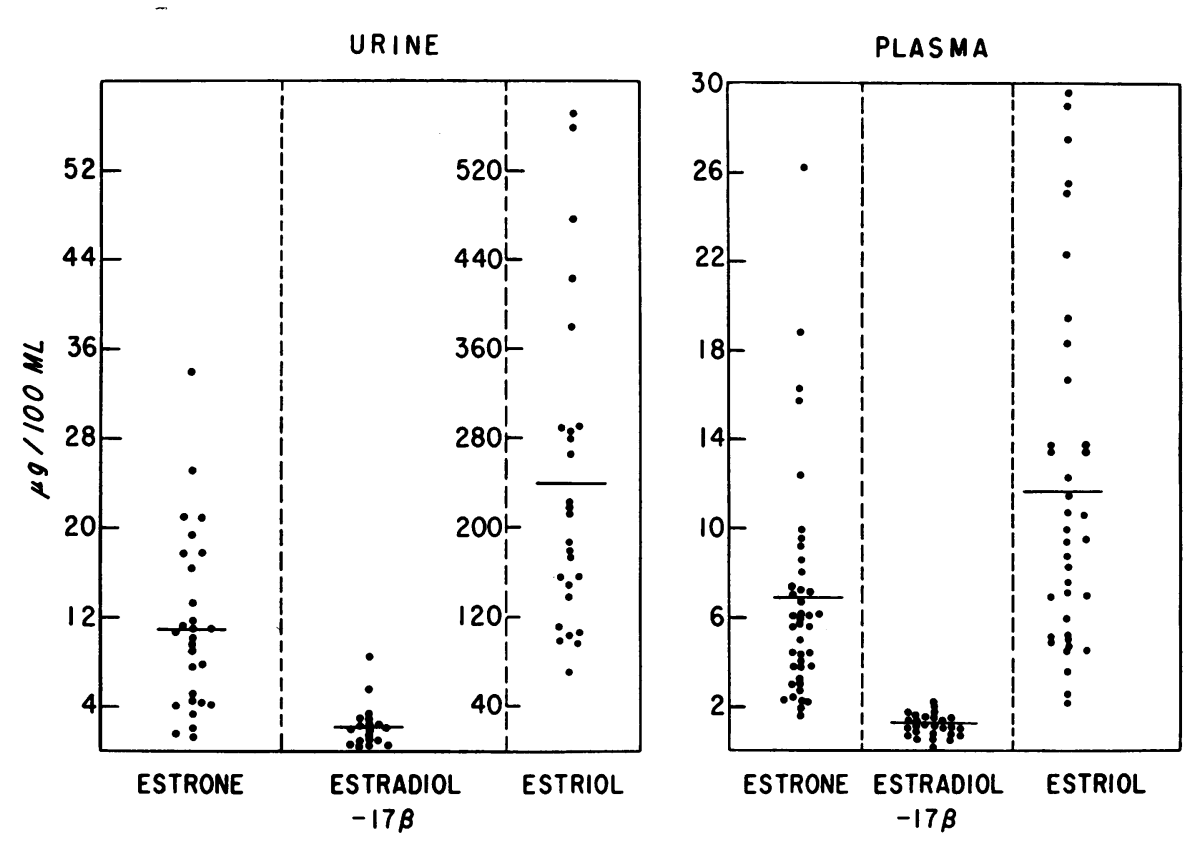

Fig. 1. Concentrations ( $\mu \mathrm{G} / 100 \mathrm{ML}$ ) of estrone, estradiol-17 $\beta$, and estriol in RanDOM SPECIMENS OF URINE AND PLASMA FROM SUBJECTS IN LATE PREGNANCY. Note 10-fold difference in scale for the urinary estriol figures. The horizontal lines in each column indicate mean values (see text).

substituted for the acidic filtrate, the plasma dilution being $1: 7$. This modification was shown by Haugen (14) to give marginally higher plasma creatinine concentrations (mean $+3 \%$ ). This method measures "creatinine chromogen," and not "true" creatinine.

Probenecid studies. After control clearance studies had been made, probenecid (Benemid), $2.5 \mathrm{~g}$, was given orally, and water intake maintained. One hour after the administration of probenecid, the bladder was emptied, and urine was discarded. Clearance studies were then repeated as in the control period.

Estrogen analysis. Plasma was separated from erythrocytes within an hour after withdrawal of the blood samples. Both plasma and urine samples were usually stored at $-15^{\circ} \mathrm{C}$ until analyzed, but in some cases the urine samples were acidified (10) and stored at room temperature. The total plasma and urine concentrations of estrone, estradiol-17 $\beta$, and estriol were estimated by the method of Preedy and Aitken (10). The recovery rates of each of the three parent estrogens when added to plasma are approximately $10 \%$ lower than their recovery when added to urine (10). This difference did not materially affect the results to be described, and consequently plasma and urine values are reported and compared without correction for methodological losses. Probenecid administration did not interfere significantly with the estrogen estimations, as judged by recovery of added estrogens. An analysis of the precision of the method when applied to plasma is given by Maner and co-workers (15).
Statistical analysis. In Figures 1 to 3, the means, standard deviations, standard errors of means, and the significance of differences between means were calculated by standard methods.

In Tables I to III the groups of paired estimations

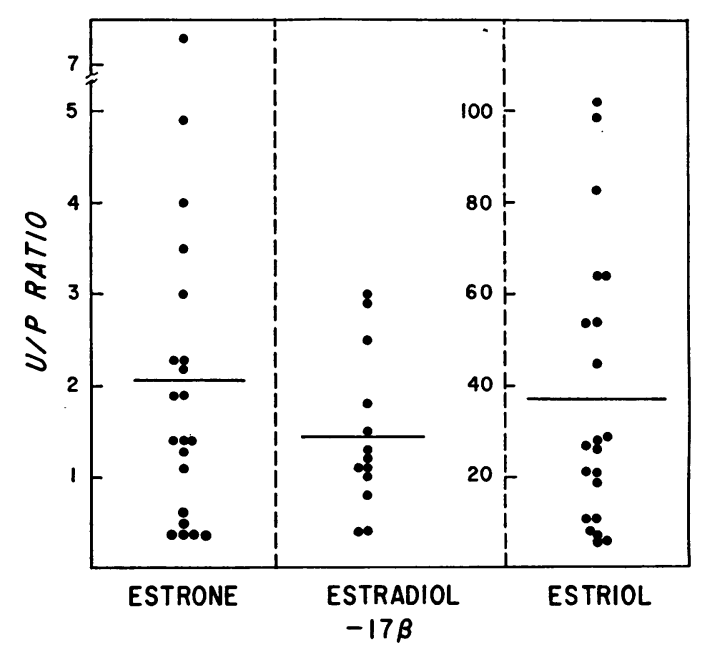

Fig. 2. Urine to Plasma concentration ratios (U/P RATIOS) OF ESTRONE, ESTRADIOL-17 $\beta$, AND ESTRIOL IN PAIRED SAMPLES FROM SUBJECTS IN LATE PREGNANCY. Horizontal lines in each column indicate mean values (see text). 
were analyzed by the paired $t$ test (16). A value for $p$ of less than 0.05 was taken as significant. This test of significance for the observed difference is based only on the variation in the differences. Other variations (e.g., subject, analytical), which have an equal effect on the two paired observations, will not influence the accuracy of the comparison. All necessary information for testing for a difference in means is therefore contained in Tables I to III.

In Figure 4 the relationship of the renal clearance of estriol to the plasma estriol concentration was expressed by the regression line constructed from the regression equation for the cubic term,

$$
y=362.614-18.891 x+0.087 x^{2}+0.008 x^{3},
$$

where $y=$ renal clearance of estriol in milliliters per minute, and $x=$ the plasma estriol concentration in micrograms per $100 \mathrm{ml}$. The relationship between the two variables was further analyzed by calculation of the correlation co-efficient, $r_{x y}$, together with the $95 \%$ confidence limits.

\section{Results}

The concentrations of estrone, estradiol-17 $\beta$ and estriol in random samples of urine and plasma taken from 41 subjects during the last 6 weeks of normal pregnancy are given in Figure 1 . Between 19 and 41 determinations were made in each category. Urine and plasma samples were not necessarily taken from the same patients. The mean urinary concentrations of estrone, estradiol-17 $\beta$, and estriol were 11.4, 2.17, and 238 $\mu \mathrm{g}$ per $100 \mathrm{ml}$, respectively. Corresponding mean concentrations in the plasma specimens were 6.64 , 1.00 , and $11.7 \mu \mathrm{g}$ per $100 \mathrm{ml}$, respectively. The ratio between the mean concentrations (estrone: estradiol-17 $\beta:$ estriol) was $5.27: 1: 110$ in urine and $6.64: 1: 11.7$ in plasma.

The relationship between the urine to plasma concentration ratios (U/P ratio) of the three estrogens in paired samples is given in Figure 2. These samples were obtained from 21 subjects. In nine of these subjects, however, the plasma estradiol-17 $\beta$ level was too low for adequate measurement. The $\mathrm{U} / \mathrm{P}$ ratios for these subjects were consequently omitted. In five of the subjects the average ratio of two or three paired samples was used. The mean $\mathrm{U} / \mathrm{P}$ ratio for estrone was 2.08

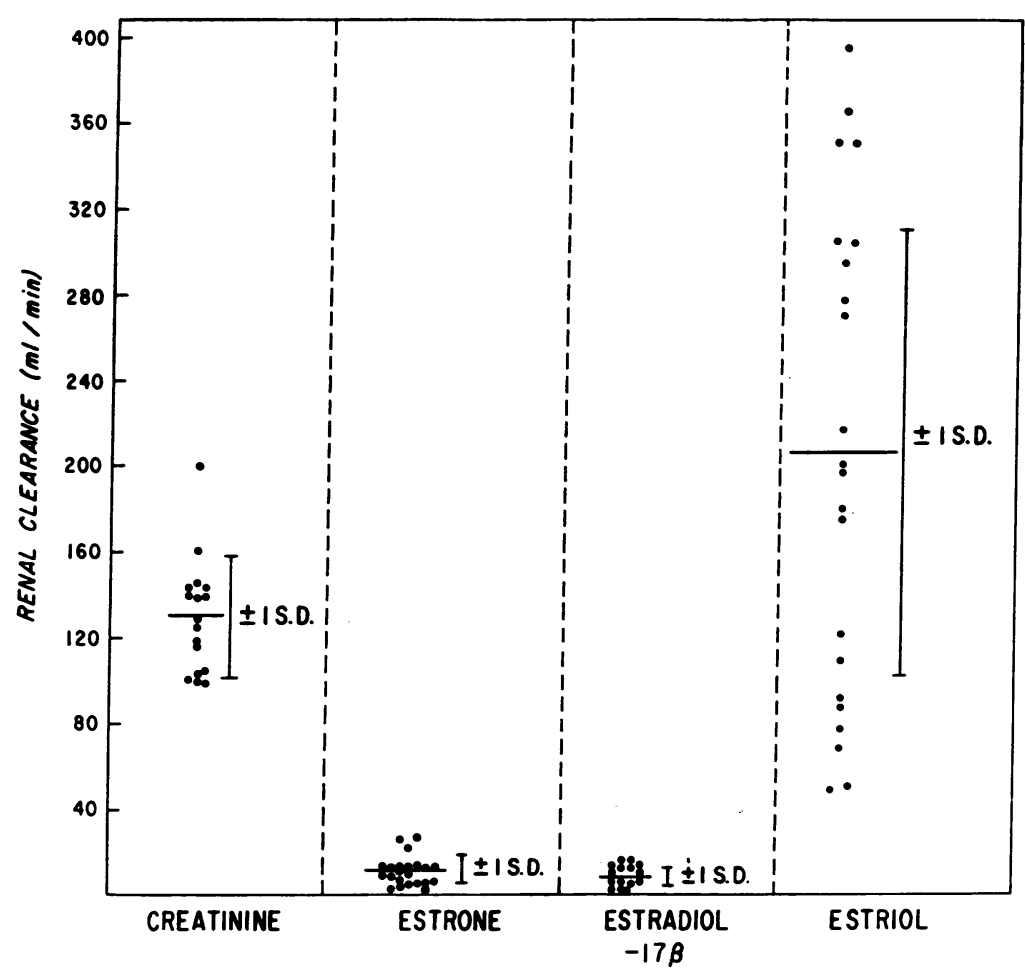

Fig. 3. RENAL CLEARANCE VALUES FOR ENDOGENOUS CREATININE, ESTRONE, ESTRAdiol-17 $\beta$, AND ESTRIOL IN LATE PREgNANCY. Horizontal lines in each column indicate mean values. Vertical lines labeled \pm 1 SD indicate one standard deviation on either side of the mean. 
TABLE I

Renal clearance of estrogens before and after probenecid administration

\begin{tabular}{|c|c|c|c|c|c|c|c|c|c|}
\hline \multirow[b]{2}{*}{ Subject } & \multicolumn{3}{|c|}{ Estrone } & \multicolumn{3}{|c|}{ Estradiol-17及 } & \multicolumn{3}{|c|}{ Estriol } \\
\hline & Before & After & Difference & Before & After & Difference & Before & After & Difference \\
\hline & \multicolumn{3}{|c|}{$\mathrm{ml} / \mathrm{min}$} & \multicolumn{3}{|c|}{$\mathrm{ml} / \mathrm{min}$} & \multicolumn{3}{|c|}{$m l / m i n$} \\
\hline $\begin{array}{l}\text { C.McW. } \\
\text { S.F.S. } \\
\text { M.B. } \\
\text { C.S. } \\
\text { P.T. } \\
\text { G.C. } \\
\text { E.M.J. } \\
\text { D.H. }\end{array}$ & $\begin{array}{r}4.1 \\
3.1 \\
8.2 \\
6.2 \\
4.2 \\
5.4 \\
6.5 \\
20.2\end{array}$ & $\begin{array}{l}0.7 \\
0.7 \\
1.4 \\
1.0 \\
3.1 \\
3.8 \\
0.8 \\
5.3\end{array}$ & $\begin{array}{r}-3.4 \\
-2.4 \\
-6.8 \\
-5.2 \\
-1.1 \\
-1.6 \\
-5.7 \\
-14.9\end{array}$ & $\begin{array}{l}3.3 \\
6.5 \\
5.9\end{array}$ & $\begin{array}{l}2.9 \\
1.9 \\
1.7\end{array}$ & $\begin{array}{l}-0.4 \\
-4.6 \\
-4.2\end{array}$ & $\begin{array}{r}172.9 \\
49.9 \\
90.9 \\
109.3 \\
49.0 \\
68.3 \\
87.4 \\
164.0\end{array}$ & $\begin{array}{l}39.9 \\
12.3 \\
26.3 \\
19.2 \\
25.0 \\
16.4 \\
22.0 \\
66.8\end{array}$ & $\begin{array}{r}-133.0 \\
-37.6 \\
-64.6 \\
-90.1 \\
-24.0 \\
-51.9 \\
-65.4 \\
-97.2\end{array}$ \\
\hline \multirow[t]{2}{*}{ Average } & 7.2 & 2.1 & & 9.1 & 2.5 & & 99.0 & 28.5 & \\
\hline & \multicolumn{2}{|c|}{$\begin{array}{r}\text { Mean difference } \\
t \\
\mathrm{p}\end{array}$} & $\begin{array}{r}-5.1 \\
3.30 \\
<0.02\end{array}$ & \multicolumn{2}{|c|}{$\begin{array}{r}\text { Mean difference } \\
t \\
\mathrm{p}\end{array}$} & $\begin{array}{r}-6.6 \\
2.83 \\
<0.05\end{array}$ & \multicolumn{2}{|c|}{$\begin{array}{r}\text { Mean difference } \\
\boldsymbol{t} \\
\mathrm{p}\end{array}$} & $\begin{array}{r}-70.5 \\
5.66 \\
<0.01\end{array}$ \\
\hline
\end{tabular}

(SE, 0.37), for estradiol-17 $\beta 1.47$ (SE, 0.28), and for estriol 37.4 ( $\mathrm{SE}, 6.65$ ). There was no significant difference between the mean $U / P$ ratios of estrone and estradiol- $17 \beta(\mathrm{p}=>0.5)$, but the $\mathrm{U} / \mathrm{P}$ ratio of estriol was significantly greater than the $\mathrm{U} / \mathrm{P}$ ratio of either estrone or estradiol$17 \beta(\mathrm{p}=<0.01)$.

The results of determinations of renal clearance of endogenous estrone and estriol in 22 subjects and of estradiol-17 $\beta$ in 15 subjects, are given in Figure 3, together with figures for the simultaneously determined endogenous creatinine clearance in 17 of the subjects. The mean renal clearance rates for estrone, estradiol-17 $\beta$, and estriol in milliliters per minute ( $\mathrm{SE}$ in parentheses) were 11.95 (1.47), 8.80 (1.07), and 205.5 (24.1), re- spectively. The mean renal clearance rate of endogenous creatinine was 131.3 (7.03). There was no significant difference between the mean clearance rates of estrone and estradiol-17 $\beta$ ( $\mathrm{p}=$ $>0.05$ ), but the clearance rate of estriol was significantly greater than that of estrone and of estradiol-17 $\beta \quad(p=<0.01)$. The mean estriol clearance rate was significantly greater than the mean endogenous creatinine clearance rate $(p=$ $<0.01)$. Of the 22 subjects in whom estriol clearances were determined, 12 had an estriol clearance that exceeded the mean creatinine clearance by more than twice the standard deviation. Of the 17 subjects in whom simultaneous estriol and creatinine clearances were determined, nine had ratios of estriol clearance to creatinine clear-

TABLE II

Urinary estrogen excretion rate before and after probenecid

\begin{tabular}{|c|c|c|c|c|c|c|c|c|c|}
\hline \multirow[b]{2}{*}{ Sub;ect } & \multicolumn{3}{|c|}{ Estrone } & \multicolumn{3}{|c|}{ Estradiol-17\% } & \multicolumn{3}{|c|}{ Estriol } \\
\hline & Before & After & Difference & Before & After & Difference & Before & After & Difference \\
\hline & \multicolumn{3}{|c|}{$\mu g / \min$} & \multicolumn{3}{|c|}{$\mu g / \min$} & \multicolumn{3}{|c|}{$\mu g / \min$} \\
\hline $\begin{array}{l}\text { C.McW. } \\
\text { S.F.S. } \\
\text { M.B. } \\
\text { C.S. } \\
\text { P.T. } \\
\text { G.C. } \\
\text { E.M.J. } \\
\text { D. H. }\end{array}$ & $\begin{array}{l}0.097 \\
0.23 \\
0.31 \\
0.62 \\
0.26 \\
0.14 \\
0.56 \\
1.16\end{array}$ & $\begin{array}{l}0.036 \\
0.053 \\
0.04 \\
0.18 \\
0.22 \\
0.10 \\
0.10 \\
0.40\end{array}$ & $\begin{array}{l}-0.061 \\
-0.177 \\
-0.27 \\
-0.44 \\
-0.04 \\
-0.04 \\
-0.46 \\
-0.76\end{array}$ & $\begin{array}{l}0.032 \\
0.036 \\
0.069\end{array}$ & $\begin{array}{l}0.027 \\
0.009 \\
0.007\end{array}$ & $\begin{array}{l}-0.005 \\
-0.027 \\
-0.062\end{array}$ & $\begin{array}{r}9.16 \\
6.85 \\
15.40 \\
24.60 \\
6.67 \\
12.60 \\
25.30 \\
26.90\end{array}$ & $\begin{array}{r}4.52 \\
1.57 \\
1.70 \\
6.40 \\
6.10 \\
4.60 \\
6.90 \\
17.60\end{array}$ & $\begin{array}{r}-4.64 \\
-5.28 \\
-13.70 \\
-18.20 \\
-0.57 \\
-8.00 \\
-18.40 \\
-9.30\end{array}$ \\
\hline \multirow[t]{2}{*}{ Average } & 0.42 & 0.14 & & 0.087 & 0.019 & & 15.93 & 6.17 & \\
\hline & \multicolumn{2}{|c|}{$\underset{t}{\text { Mean difference }}$} & $\begin{array}{r}-0.28 \\
2.97 \\
<0.02\end{array}$ & \multicolumn{2}{|c|}{$\underset{t}{\operatorname{Mean} \text { difference }}$} & $\begin{array}{c}-0.068 \\
2.75 \\
<0.06\end{array}$ & Mea1 & $\begin{array}{c}\text { lifference } \\
t \\
\mathrm{p}\end{array}$ & $\begin{array}{r}-9.76 \\
4.24 \\
<0.01\end{array}$ \\
\hline
\end{tabular}


TABLE III

Plasma estrogen concentration before and after probenecid

\begin{tabular}{|c|c|c|c|c|c|c|c|c|c|}
\hline \multirow[b]{2}{*}{ Subject } & \multicolumn{3}{|c|}{ Estrone } & \multicolumn{3}{|c|}{ Estradiol-17 $\beta$} & \multicolumn{3}{|c|}{ Estriol } \\
\hline & Before & After & Difference & Before & After & Difference & Before & After & Difference \\
\hline & \multicolumn{3}{|c|}{$\mu g / 100 \mathrm{ml}$} & \multicolumn{3}{|c|}{$\mu g / 100 \mathrm{ml}$} & \multicolumn{3}{|c|}{$\mu g / 100 \mathrm{ml}$} \\
\hline $\begin{array}{l}\text { C.McW. } \\
\text { S.F.S. } \\
\text { M.B. } \\
\text { C.S. } \\
\text { P.T. } \\
\text { G.C. } \\
\text { E.M.J. } \\
\text { D.H. } \\
\text { P.J. }\end{array}$ & $\begin{array}{l}2.3 \\
7.3 \\
3.8 \\
9.9 \\
6.1 \\
2.5 \\
8.6 \\
6.8 \\
3.8\end{array}$ & $\begin{array}{r}5.0 \\
17.0 \\
9.2 \\
18.2 \\
6.8 \\
2.6 \\
12.6 \\
7.9 \\
6.3\end{array}$ & $\begin{array}{l}+2.7 \\
+9.7 \\
+5.4 \\
+8.3 \\
+0.7 \\
+0.1 \\
+4.0 \\
+1.1 \\
+2.5\end{array}$ & $\begin{array}{l}0.94 \\
0.56 \\
1.16 \\
1.90 \\
1.20 \\
0.13 \\
1.20 \\
1.03 \\
2.10\end{array}$ & $\begin{array}{r}0.91 \\
1.13 \\
1.13 \\
<0.05 \\
<0.85 \\
0.10 \\
1.90 \\
1.05 \\
1.70\end{array}$ & $\begin{array}{l}-0.03 \\
+0.57 \\
-0.03 \\
-1.85 \\
-0.35 \\
-0.03 \\
+0.70 \\
+0.02 \\
-0.40\end{array}$ & $\begin{array}{r}5.2 \\
13.8 \\
16.9 \\
22.5 \\
13.6 \\
13.5 \\
29.0 \\
19.5 \\
13.8\end{array}$ & $\begin{array}{l}11.2 \\
18.6 \\
19.2 \\
33.6 \\
24.6 \\
22.9 \\
31.4 \\
26.5 \\
23.8\end{array}$ & $\begin{array}{r}+6.0 \\
+4.8 \\
+2.3 \\
+11.1 \\
+11.0 \\
+9.4 \\
+2.4 \\
+7.0 \\
+10.0\end{array}$ \\
\hline \multirow[t]{2}{*}{ Average } & 5.7 & 9.5 & & 1.14 & 0.98 & & 16.2 & 23.5 & \\
\hline & Mean d & $\begin{array}{c}\text { fference } \\
t \\
\mathrm{p}\end{array}$ & $\begin{array}{r}+3.83 \\
3.39 \\
<0.01\end{array}$ & Mean & $\begin{array}{c}\text { difference } \\
t \\
\mathrm{p}\end{array}$ & $\begin{array}{r}-0.16 \\
0.80 \\
>0.50\end{array}$ & Mean d & $\begin{array}{c}\text { fference } \\
t \\
\mathrm{p}\end{array}$ & $\begin{array}{r}7.1 \\
6.12 \\
<0.01\end{array}$ \\
\hline
\end{tabular}

ance that exceeded 1.00. The ratios in these nine subjects were $2.08,2.06,2.00,1.96,1.73$, $1.65,1.44,1.22$, and 1.07 .

The effect of probenecid administration on the renal clearance rates of estrone and estriol in eight subjects, and of estradiol-17 $\beta$ in five subjects, are given in Table I. In all subjects there was a fall in the clearance rate of each of the three estrogens. The mean differences between clearance rates before and after probenecid were these: estrone, $-5.1 \mathrm{ml}$ per minute $(\mathrm{p}=0.02)$; estradiol$17 \beta,-6.6 \mathrm{ml}$ per minute $(\mathrm{p}=<0.05)$; and estriol, $-70.5 \mathrm{ml}$ per minute $(\mathrm{p}=<0.01)$. The $p$ figures indicate that the fall was significant in each group. With the mean clearance rate after probenecid expressed as a percentage of the mean control rate, the values obtained were 29,27 , and 29 for estrone, estradiol-17 $\beta$, and estriol, respectively.

In Table II the effects of probenecid upon the urinary excretion rates of estrone, estradiol-17 $\beta$, and estriol in the same subjects are shown. A diminished excretion of each of the three estrogens occurred in each subject in whom determinations were made. The mean differences between excretion rates before and after probenecid in micrograms per minute were as follows: estrone, -0.28 ; estradiol-17 $\beta,-0.068$; and estriol, -9.67. These differences were significant $(\mathrm{p}=$ $<0.02$ ) for estrone and estriol and of borderline significance for estradiol-17 $\beta(\mathrm{p}=<0.06)$.

In Table III the plasma estrogen concentrations before and after probenecid administration are given. Each subject showed an increased plasma concentration of estrone and estriol after probenecid. The mean differences between plasma concentrations before and after probenecid in micrograms per $100 \mathrm{ml}$ were $+3.83(\mathrm{p}=<$ $0.01)$ for estrone and $+7.1(\mathrm{p}=<0.01)$ for estriol. For estradiol-17 $\beta$ the mean difference, $-0.16 \mu \mathrm{g}$ per $100 \mathrm{ml}$, was not significant. This may have been due to the low concentration of estradiol-17 $\beta$ found in some samples, with a con-

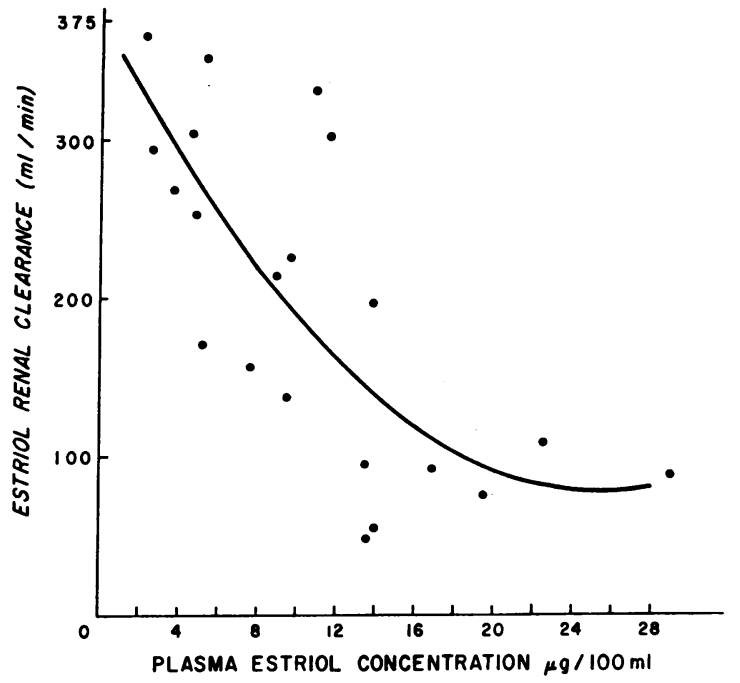

Fig. 4. RELATIONSHiP BETWEen the RENAL CLEARANCE AND PLASMa CONCENTRATION of ESTRIOL. The fitted line was calculated as described under Statistical analysis. 
sequent increase in the error of the estradiol-17 $\beta$ determinations.

In the case of estrone and estradiol-17 $\beta$ no significant relationship could be established between the plasma concentration of the estrogens and their respective clearance rates. However, a relationship appeared to exist in the case of estriol. This is shown in Figure 4, where plasma estriol concentration in micrograms per $100 \mathrm{ml}$ is plotted against renal estriol clearance in milliliters per minute. The relationship is best defined by the fitted line, calculated as described under Statistical analysis. The correlation coefficient, $r_{x y}$, is -0.70 , and $r_{x y}^{2}$ is 0.49 . The $95 \%$ confidence limits are -0.38 and -0.87 , indicating the significance of the correlation.

\section{Discussion}

The results reported in this study have to be interpreted with particular regard to the limitations of the methods of analysis. The methods employed measure separately the total amounts of estrone, estradiol-17 $\beta$, and estriol present in plasma and urine. They provide no information about the various physicochemical forms in which these hormones may exist, such as the nature and extent of conjugation with glucuronic, sulfuric, or other acids, and no information regarding the degree of binding to the plasma proteins of either free (i.e., unconjugated) or conjugated steroid.

Furthermore, it is unlikely that the three estrogens exist in the same physicochemical forms in both urine and plasma. It is also probable that the various moieties contributing to a total estrogen as measured in this study will have different renal clearance rates. Binding to plasma proteins may alter the availability of free or conjugated steroids for renal excretion. All these factors may clearly affect any deductions based on or involving a comparison between plasma and urine estrogen concentrations. Consequently $U / P$ ratios and renal clearance rates of estrone, estradiol$17 \beta$, and estriol should be regarded not necessarily as values for single substances, but as composite values for the various $U / P$ ratios and clearance rates of the moieties composing total estrone, estradiol-17 $\beta$, and estriol respectively.

The data given in Figure 1 permit a comparison of estrogen concentration ratios in urine with those in plasma in late pregnancy, from the analy- sis of a large number of random samples. Whereas the mean concentration ratio of estrone to estradiol- $17 \beta$ is similar both in urine and plasma, the mean concentration ratio of estriol to either estrone or estradiol-17 $\beta$ is markedly different, the ratios being approximately 10 times higher in urine than in plasma, confirming the impression previously referred to (11).

A comparison of estrogen $U / P$ ratios by using paired samples (Figure 2) showed that the mean $U / P$ ratios of estrone and of estradiol- $17 \beta$ do not differ significantly, but that the mean $U / P$ ratio of estriol was approximately 20 times greater than the mean $U / P$ ratio of either estrone or estradiol- $17 \beta$, a statistically significant difference.

It was to be expected that the renal clearance values for the three estrogens would preserve this general relationship. This is confirmed by finding that the mean clearance rates for estrone, estradiol-17 $\beta$, and estriol were $11.95,8.80$, and 205 $\mathrm{ml}$ per minute, respectively, the latter clearance rate being significantly different from the other two rates.

The values in Figure 3 indicate a wider scatter of the estriol clearance rates compared with those of estrone and estradiol-17 $\beta$. This is, however, merely a function of the larger values of the estriol clearance, since the coefficients of variation in each group were similar (estrone, 58; estradiol$17 \beta, 56$; and estriol, 55).

Simultaneous inulin and estrogen clearances could not be estimated in our subjects, since the presence of inulin interfered with the determination of urinary estrogens by greatly reducing recovery. This could not be overcome by dilution of the urine, as in the case of glucose (17).

A comprehensive study by Sims and Krantz (18) has shown that in the last 4 to 6 weeks of pregnancy the mean endogenous creatinine: inulin clearance ratio is 0.97 , SD 0.15 , so that it might be assumed that the creatinine clearances obtained in the present study would give a good indication of the glomerular filtration rates in our subjects.

Sims and Krantz (18), however, measured the clearance of "true" creatinine, which has been shown $(19,20)$ to correspond very closely to the inulin clearance, whereas the Brod and Sirota method (13) we used measures the "creatinine 
chromogen" clearance. Since the latter method gives somewhat higher plasma "creatinine" levels, creatinine clearance values lower than the simultaneously determined inulin clearance would be expected. In fact, however, Brod and Sirota (13) found a mean "creatinine chromogen": inulin clearance ratio of 1.00 in a series of normal subjects. Our own experience, using substantially the same methods, has yielded ratios somewhat greater than unity in a small number of normal subjects. No significant difference was found between the inulin clearance figures in the last 6 weeks of pregnancy reported by Sims and Krantz (18) and the creatinine clearances in the present study. However, Doolan, Alpen, and Theil (19) found that in the normal subject the mean "true" creatinine: inulin clearance ratio was 1.03 , whereas with the Brod and Sirota method (13), the ratio was 0.86 .

Although our creatinine clearance values probably provide a good estimate of the glomerular filtration rate, they may possibly underestimate the glomerular filtration rate by approximately $15 \%$ (19). Even if this were so, it will be observed from Figure 3, and from the values given in the results section, that the relationship between the creatinine clearance and the clearance of each of the three estrogens would not be substantially affected.

Figure 3 shows that the mean renal clearance rates of estrone and estradiol-17 $\beta$ are approximately $10 \%$ of the mean creatinine clearance. The mean clearance of estriol is approximately twice the mean creatinine clearance, the difference being highly significant. In 12 of 22 subjects the estriol clearance rate exceeded the mean creatinine clearance rate by more than twice the standard deviation, and in 9 of 17 subjects the estriol : creatinine clearance ratio lay between 1.07 and 2.08 . We can therefore reasonably assume that in most of these subjects at least estriol was being secreted by the renal tubule.

Further information regarding the renal clearance of the three estrogens is obtained from the probenecid studies (Tables I to III). The significant mean decrease in the renal clearance of estriol, accompanied both by a decreased urinary excretion rate and a rise in plasma concentration after the administration of probenecid, can best be explained by the established action of probe- necid in blocking transfer of many substances across the renal tubule cells and provides further evidence for the renal tubular secretion of estriol.

A similar marked decrease in the renal clearance of estrone and estradiol-17 $\beta$ occurred after probenecid administration (Table I), again accompanied by a decrease in urinary excretion rate and a rise in plasma concentration of the two estrogens (Tables II and III). This suggests that in spite of the low initial clearance values, some moiety of total estrone and of estradiol-17 $\beta$ may also be secreted by the renal tubule. Because of the evidence for the renal tubular secretion of the three estrogens, particularly estriol, evidence was sought for the existence of a tubular secretion maximum $\left(\mathrm{T}_{\mathbf{m}}\right)$ by an examination of the relationship between plasma concentration and renal clearance of each of the estrogens. A relationship was found to exist in the case of estriol only (Figure 4). This is expressed by the fitted curve. The square of the correlation coefficient $\left(\mathrm{r}_{\mathrm{xy}}^{2}\right)$ indicates that approximately $50 \%$ of the variation of the renal clearance of estriol can be explained by dependence on the plasma estriol concentration. The shape of the curve is similar to that expected in the presence of a $T_{m}$ (21). The considerable scatter of points may be due to each point representing a different subject. Although the existence of a $T_{m}$ is the most likely explanation of these results, other factors, such as increased protein binding of estriol at higher plasma levels, cannot be excluded.

Evidence for the tubular secretion of other steroid hormones and their metabolites in the human has been reported. Bongiovanni and Eberlein (3) found in one subject a progressive decrease in renal clearance of administered androsterone as the plasma levels were raised, suggesting the presence of a $T_{m}$. Probenecid has been shown to reduce the renal clearance of crude 17ketosteroids (4), and of glucosiduronate 17-hydroxycorticoids, but not of free 17-hydroxycorticoids (6).

In the human, the glucosiduronates of steroid hormones and their metabolites appear in general to have higher renal clearance rates than the nonconjugated steroids, particularly in the plasma 17-hydroxycorticoids $(5,6)$. In the above mentioned studies, however, the renal clearance of glucosiduronate steroids rarely exceeded the en- 
dogenous creatinine clearance, whereas in our series the clearance rate of estriol exceeded the mean creatinine clearance by a significant amount in approximately half the subjects.

There is a good evidence for the renal tubular secretion of nonsteroidal glucosiduronates, such as salicylacyl and salicylphenyl glucosiduronates in the human (22) and of various phenol glucosiduronates, but not the free phenols, in the chicken and goat (23).

Because of this evidence, and since the majority of urinary estriol in late pregnancy is in the glucosiduronate form (24), it appears likely that the moiety of total plasma estriol which contributes chiefly to the high estriol clearance rates reported here is a glucosiduronate of estriol.

\section{Summary}

The renal clearance of endogenous estrogens in late pregnancy has been studied in subjects in late pregnancy. Concentrations of endogenous estrone, estradiol-17 $\beta$, and estriol in the plasma and urine samples used in the studies were determined after acid hydrolysis and ether extraction.

The urine: plasma concentration ratios (U/P ratios) and renal clearance values for estrone and estradiol-17 $\beta$ differed markedly from those for estriol. The mean $\mathrm{U} / \mathrm{P}$ ratios for estrone and estradiol- $17 \beta$ were 2.08 and 1.47 , respectively, and the mean $U / P$ ratio for estriol was 37.4. The mean renal clearances for estrone and estradiol$17 \beta$ were 11.95 and $8.80 \mathrm{ml}$ per minute, respectively, and the mean renal clearance of estriol was $205.5 \mathrm{ml}$ per minute, a value significantly higher than the simultaneously determined mean endogenous creatinine clearance of $131.3 \mathrm{ml}$ per minute. This indicates that estriol is secreted in part at least by the renal tubule, probably as a glucosiduronate.

Probenecid administration reduced the urinary excretion rate and renal clearance of all three estrogens, at the same time raising the plasma estrogen concentration. This suggests that in spite of initial low clearance values, both estrone and estradiol-17 $\beta$ also are partly excreted by the renal tubule.

Some evidence for the existence of a tubular maximal secretion rate $\left(T_{m}\right)$ for estriol was found.

\section{Acknowledgment}

We are greatly indebted to Mrs. Gladys H. Reynolds, Mathematical Statistician, Statistics Section, U. S. Public Health Service, Communicable Disease Center, Atlanta, Ga., for much help and advice with the statistical analysis.

\section{References}

1. Brown, C. H., B. D. Saffan, and J. R. K. Preedy. Renal handling of estrogens in late pregnancy (abtract). J. clin. Invest. 1960, 39, 975.

2. Schedl, H. P., P. S. Chen, Jr., G. Greene, and D. Redd. The renal clearance of plasma cortisol. J. clin. Endocr. 1959, 19, 1223.

3. Bongiovanni, A. M., and W. R. Eberlein. The renal clearance of neutral 17-ketosteroids in man. J. clin. Endocr. 1957, 17, 238.

4. Jacono, G., A Brancaccio, B. D'Alessandro, and R. DeLuca. The effect of hydrochlorothiazide on the clearances of free and conjugated 17-hydroxycorticosteroids, total 17-ketosteroids, dehydroepiandrosterone and androsterone. Endocrinology 1961, 69, 231.

5. Kornel, L. Renal clearance of endogenous 17-hydroxycorticosteroids in hypertension. J. clin. Endocr. 1960, 20, 1445.

6. Daughaday, W. H. Binding of corticosteroids by plasma proteins. I. Dialysis equilibrium and renal clearance studies. J. ciin. Invest. 1956, 35, 1428.

7. Weichselbaum, T. E., A. I. Mendeloff, H. W. Margraf, and M. Sheppard, Jr. Hepatic conjugation and renal clearance of 17-hydroxycorticosteroids in man. Fed. Proc. 1955, 14, 301.

8. Bongiovanni, A. M., and W. R. Eberlein. Determination, recovery, identification and renal clearance of conjugated adrenal corticoids in human peripheral blood. Proc. Soc. exp. Biol. (N. Y.) 1955, 89, 281.

9. Roy, E. J., and J. B. Brown. A method for the estimation of oestriol, oestrone and oestradiol- $17 \beta$ in the blood of the pregnant woman and of the foetus. J. Endocr. 1960, 21, 9.

10. Preedy, J. R. K., and E. H. Aitken. The determination of estrone, estradiol-17 $\beta$, and estriol in urine and plasma with column partition chromatography. J. biol. Chem. 1961, 236, 1300.

11. Preedy, J. R. K. in Conference to Evaluate Methods for Determining Estrogens in Body Fluids and Tissues, G. Pincus, Ed. Worcester Found. exp. Biol., Shrewsbury, Mass., Aug. 1957, p. 156.

12. Smith, H. W. The Kidney. New York, Oxford University Press, 1951, pp. 39-45.

13. Brod, J., and J. H. Sirota. The renal clearance of endogenous "creatinine" in man. J. clin. Invest. 1948, 27, 645.

14. Haugen, $H$. N. The determination of endogenous "creatinine" in plasma and urine. Scand. J. clin. Lab. Invest. 1953, 5, 48.

15. Maner, F. D., B. D. Saffan, R. A. Wiggins, J. D. Thompson, and J. R. K. Preedy. Interrelationship 
of estrogen concentrations in the maternal circulation, fetal circulation and maternal urine in late pregnancy. J. clin. Endocr. 1963, 23, 445.

16. Bennett, C. A., and N. L. Franklin. Statistical Analysis in Chemistry and the Chemical Industries. New York, John Wiley \& Sons, 1954, pp. 376-379.

17. Hobkirk, R., P. R. Blahey, A. Alfheim, J. I. Raeside, and G. E. Jordon. Urinary estrogen excretion in normal and diabetic pregnancy. J. clin. Endocr. $1960,20,805$.

18. Sims, E. A. H., and K. E. Krantz. Serial studies of renal function during pregnancy and the puerperium in normal women. J. clin. Invest. 1958, 37, 1764.

19. Doolan, P. D., E. L. Alpen, and G. B. Theil. A clinical appraisal of the plasma concentration and endogenous clearance of creatinine. Amer. J. Med. 1962, 32, 65.

20. Haugen, H. N., and E. M. Blegen. The true endogenous creatinine clearance. Scand. J. clin. Lab. Invest. 1953, 5, 67.

21. Smith, H. W. The Kidney. New York, Oxford University Press, 1951, p. 175.

22. Schachter, D., and J. G. Manis. Salicylate and salicyl conjugates: fluorimetric estimation, biosynthesis and renal excretion in man. J. clin. Invest. $1958,37,800$.

23. Sperber, I. The excretion of some organic bases and some phenols and phenol derivatives. Scand. J. clin. Lab. Invest. 1949, 1, 345.

24. Diczfalusy, E., and Ch. Lauritzen. Oestrogene beim Menschen. Berlin, Springer Verlag, 1961, p. 103. 